\title{
Evaluation of osteoporotic trochanteric fractures treated with cement-augmented dynamic hip screw
}

\author{
Rahul Kumar Chandan*, Dharampal Verma, R. C. Meena, Jakir Husain
}

Department of Orthopaedics, SMS Medical College, Jaipur, Rajasthan, India

Received: 24 May 2016

Revised: 04 June 2016

Accepted: 30 June 2016

\author{
*Correspondence: \\ Dr. Rahul Kumar Chandan, \\ E-mail: rahulkr0987@gmail.com
}

Copyright: (C) the author(s), publisher and licensee Medip Academy. This is an open-access article distributed under the terms of the Creative Commons Attribution Non-Commercial License, which permits unrestricted non-commercial use, distribution, and reproduction in any medium, provided the original work is properly cited.

\begin{abstract}
Background: Dynamic hip screw (DHS) has been the standard treatment for stable trochanteric fracture patterns. However, primary stabilization with dynamic/sliding hip screw is not always successful, especially in osteoporotic fractures. Internal fixation in such a situation may achieve a satisfactory initial fracture site reduction, but late fracture collapse into varus during weight bearing, can lead to a high failure rate. Since 1975, polymethylmethacrylate (PMMA) cement-augmented DHS have been used as a solution in unstable ITFs by adding an anchoring ability to the lag screw.

Methods: A series of 33 osteoporotic intertrochanteric fractures were operated with cement augmented dynamic hip screw. One patient lost to follow up. All patients were then allowed partial weight bearing walker aided ambulation under the guidance of physiotherapist on the second or third postoperative day. The patients were followed radio logically and clinically at regular intervals (1st month, than at 3rd month and then at 6th month interval after surgery). Results were graded as excellent (score >31), good (score 24-31), fair (score 16-23), and poor (score <16). Clinical result was given according to Salvati and Wilson scoring.

Results: Total 33 patients were taken for the study they were followed for minimum 6 months and at 6 months the clinical outcome was rated as per the Salvati and Wilson scoring system. One patient lost to follow-up. Final clinical results as evaluated by Salvati and Wilson scoring were; excellent in 24 cases (75\%), good in 7 cases $(21.88 \%)$, fair in 1 case $(3.12 \%)$ and poor in 0 cases $(0 \%)$. There were no non-union, AVN, implant failure and screw cut-out in our study.

Conclusions: The surgical management of intertrochanteric fractures with PMMA augmented DHS provide a stable fixation with moderate pain free early mobilisation and better outcome in osteoporotic patients without the complications of superior screw cut-out, sliding collapse, and with the appropriate placement of bone cement along with proper amount $(4-5 \mathrm{ml})$ of cement we can also reduce the cement related complications such as delayed healing, nonunion, heat necrosis and avascular necrosis.
\end{abstract}

Keywords: Dynamic hip screw, Osteoporosis, Screw cut out, Polymethylmethacrylate, Salvati and Wilson score

\section{INTRODUCTION}

Intertrochanteric fracture is one of the most common fractures of the hip especially in elderly with osteoporotic bones usually due to low energy trauma like simple falls. These fractures have bimodal age distribution with $90 \%$ occurring after 50 years of age by minimal to moderate physical trauma in areas of bone significantly affected by osteoporosis. This incidence doubles every 10 years after 50 years of age. ${ }^{1,2}$

This increased incidence with increasing age can be attributed to osteoporosis and bone loss which in turn is due to decreased physical activity. ${ }^{3-6}$ As life expectancy is 
increasing so is the number of intertrochanteric fractures. Osteoporotic females out number males in incidence (2$3: 1)$.

Before the introduction of suitable fixation devices, treatment of intertrochanteric fractures was nonoperative, consisting of prolonged bed rest in traction until fracture healing occurred (usually 10-12 weeks ), followed by a lengthy programme of ambulation training. In elderly patients, this approach was associated with high complication rates; typical problems included decubitus ulcers, urinary tract infection, joint contractures, pneumonia and thromboembolic complications, resulting in a high mortality rate. In addition, fracture healing was generally accompanied varus deformity and shortening because of the inability of traction to effectively counteract the deforming muscular forces. That's why intertrochanteric fractures are almost always treated by early internal fixation to obtain the best possible position and to get early mobilization thereby reducing the risk of prolonged recumbency.

Various devices for the internal fixation of Intertrochanteric fracture used now a days are dynamic hip screw, intramedullary nailing with sliding hip screw and arthroplasty. The use of static implants with fixed angle at nail plate junction is no longer justified since DHS has given uniformly good results due to controlled impaction and stable contact of the fragments. The sliding hip screw has gained universal popularity as the fixation device for Intertrochanteric fractures. DHS is gold standard. Majority of technical failures however consist of collapse of fracture area and cutting out of neck screw caused by rotation potential of head neck fragment and/or malpositioning of neck screw. Despite the wide spread use of these implants failure rate as high as 8 $17 \%$ is reported in some series.

Dynamic hip screw (DHS) has been the standard treatment for stable trochanteric fracture patterns. However, primary stabilization with dynamic/sliding hip screw is not always successful, especially in osteoporotic fractures. Low bone mineral density and thin cortices are not only major risk factors for hip fractures, but also contribute to the failure of fracture fixation in elderly patients on account of excessive collapse and lag screw cut-out from the superior aspect. ${ }^{8-10}$ Internal fixation in such a situation may achieve a satisfactory initial fracture site reduction, but late fracture collapse into varus during weight bearing, can lead to a high failure rate. ${ }^{11}$ Mechanical stability after fixation in these fractures is dependent on the quality of bone, fracture personality, quality of reduction, and choice of implants. ${ }^{12}$ In the past, various methods such as valgus osteotomy, valgus reduction with tension-band wiring, lateral wall reconstruction, and a variety of other techniques have been developed, in an attempt to reduce the rate of complications in the management of these fractures. ${ }^{13-16}$ However, none of these have been able to completely address the problem of implant failure in osteoporotic patients, due to a superior screw cut out. ${ }^{15,16}$ Since 1975 , polymethylmethacrylate (PMMA) cement-augmented DHS have been used as a solution in unstable ITFs by adding an anchoring ability to the lag screw. ${ }^{16}$ Some encouraging results have been observed, showing a higher success rate and better functional recovery than with conventional DHS. ${ }^{17,18}$ But the technique has not gained wide acceptance due to associated complications like delayed union and nonunion. ${ }^{16-19}$

The objective of augmentation with bone cement is to provide immediate strength to aid lag screw anchorage and early weight bearing.

This prospective study was conducted to evaluate the outcome and efficacy of PMMA augmented DHS in elderly osteoporotic patients with intertrochanteric fractures.

\section{METHODS}

The study was conducted prospectively on the patients with intertrochanteric fractures who got admitted during April 2014 to June 2015 with follow up of minimum 6 months.

Patients with closed intertrochanteric fracture, age more than 60 years, DEXA T Score $\leq-2.5$ were included in the study after taking written consent form from them.

Exclusion criteria were open fracture, subtrochanteric fracture, pathological fracture, intracapsular fracture neck of femur, patient with multiple injuries, patients who were non ambulatory prior to their injury, patient with dementia severe enough to limit their ability to comply with postoperative rehabilitation.

A total of 33 patients went through the procedure who got admitted and met the criterias. 1 patient lost to follow up.

\section{Subject enrolment}

Patients who have fulfilled the inclusion and exclusion criteria, all the study subjects were chosen from casualty and orthopaedic OPD with intertrochanteric fractures. All patients were informed about all the possible modalities of treatment and the superiority of dynamic hip screw fixation over others and about the benefits of cement augmentation in an osteoporotic bone over non augmentation, only the patients who had given their consent were operated by cement augmentation and included in study.

\section{Preoperative evaluation}

Detailed history was taken about the traumatic event, comorbid conditions and any on-going medication specially any anticoagulant. Detailed Physical examination was performed in every case and documentation was done. Patients were put on analgesic support, preoperatively. 
Dual energy X-ray absorptiometry (DEXA) scan of the contra lateral hip of the patients were done and only those patients with established osteoporosis ( $\mathrm{T}$ score <-2.5) were included in the study. All fractures were classified on the basis of AO classification.

All routine investigations were sent including - complete blood count, blood grouping, fasting and random blood sugar, liver function and Renal Function tests, ECG, urine routine and microscopy, $\mathrm{x}$-ray chest $\mathrm{AP}$ view and viral markers.

Pre-anaesthetic check-up was done on a day prior to surgery with clearance from concerned speciality in case of co-morbid conditions. Patient as well as family members were explained about the surgery and the risk factors, and the consent for the same was taken.

\section{Operative procedure}

All surgeries were performed on the radiolucent table with patient in the supine position. Prophylactic antibiotic was administered half an hour prior to surgery, part preparation done after appropriate anaesthesia. All surgeries were performed using Lateral approach, reduction achieved under image intensifier. Guide wire was passed central to femoral neck, confirmed under Carm in both AP and lateral view care was taken not to perforate the femoral head.

After depth measurement triple reaming and tapping was done. Another guide wire was placed above and parallel to first one and then first guide wire was removed and PMMA bone cement of around 10 to $15 \mathrm{ml}$ was mixed and placed in a disposable injection type of syringe attached with cement gun as shown in Figure 1 and 2 in a semi liquid state. The long and narrow nozzle of the syringe was inserted into the hole femoral canal. As the piston was pressed, the barrel was pulled back slowly, so as to inject cement from the deepest part of the head outward, up to the base of the femoral head as in Figure 3.

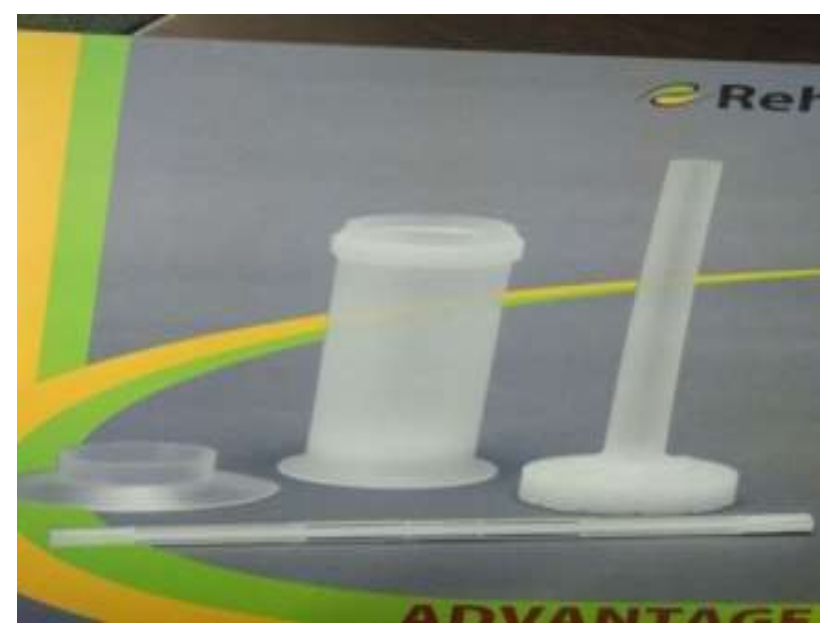

Figure 1: Disposable syringe with long nozzle.

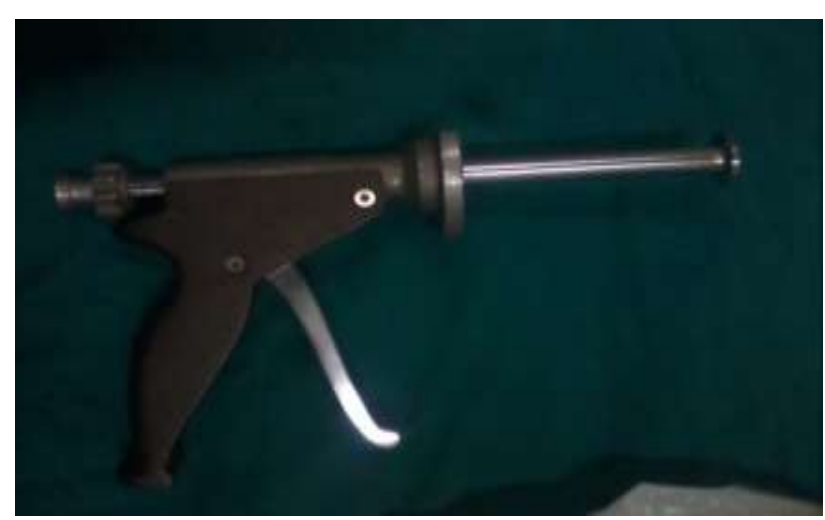

Figure 2: Cement gun.

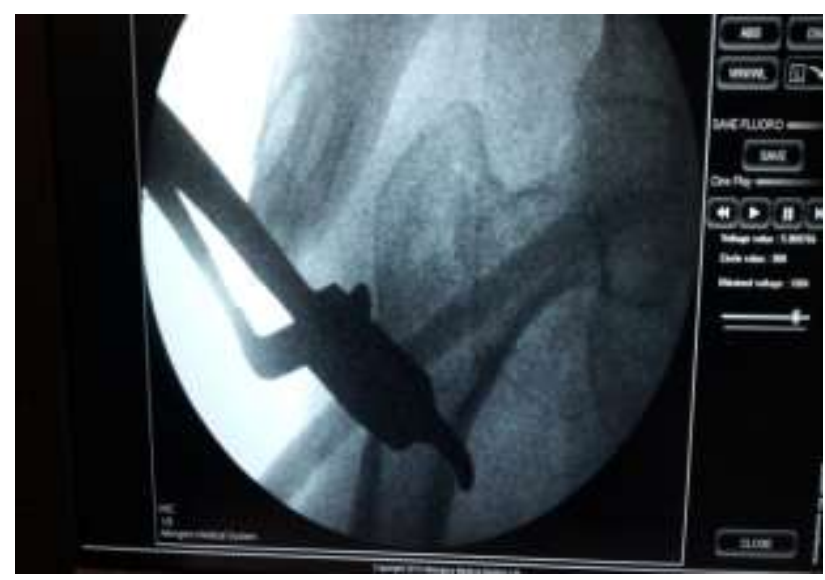

Figure 3: C-arm image while depositing cement by the use of injection type syringe.

Finally the lag screw of appropriate size and then plate was applied, haemostasis achieved, wound closure was done in layers after placing drain.

\section{Post operative period}

Vitals monitoring done for first 24 hours, postoperative blood transfusion done (if haemoglobin was <8). Analgesics and other medication used as required. CBC, RFT on first postoperative day were done. DVT prophylaxis was started on first postoperative day and the protocol was same for all patients, bed side sitting on first postoperative day with active and passive exercises.

On second postoperative day we have done radiological assessment with Antero-posterior and lateral view of hip involved and the length from the tip of lag screw to the lateral barrel plate and tip apex distance (TAD) was also assessed. The degree of sliding was calculated by measuring the change in the length from tip of lag screw to the lateral barrel plate in follow up and compared with immediate postoperative calculated length. TAD is the sum of the distances from the tip of lag screw to the apex of femoral head on both AP and lateral radiographic views, it predicts the lag screw position within the femoral head and is believed to be an independent predictor of lag screw cut out. A TAD of less than $20 \mathrm{~mm}$ 
result in a zero percent occurrence of screw cut out (as cut-out associate with screw positioning). Dressing with drain removal was done on second postoperative day. All patients were then allowed partial weight bearing walker aided ambulation under the guidance of physiotherapist on the second or third postoperative day. Patient discharged after full rehabilitation and with proper discharge advice. Suture removal done after 2 weeks.

\section{Follow up}

The patients were followed radio logically and clinically at regular intervals $\left(1^{\text {st }}\right.$ month, than at $3^{\text {rd }}$ month and then at $6^{\text {th }}$ month interval after surgery). The clinical outcome was rated as per Salvati and Wilsons score. Final radiological evaluation will include non-union, screw cut out, the extent of sliding collapse and varus collapse.

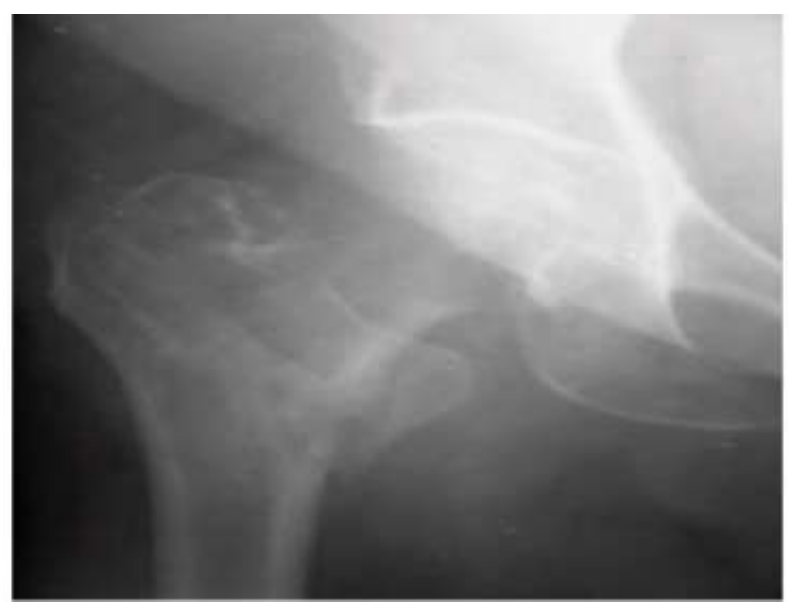

Figure 4: Preoperative X-ray.

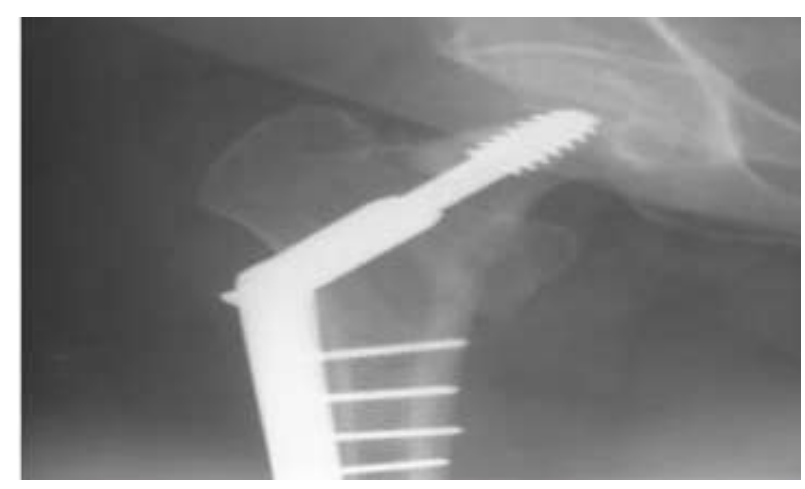

Figure 5: Postoperative X-ray.

All patients were allowed partial weight bearing ambulation under the guidance of a physiotherapist on the second or third postoperative days, and were allowed full weight bearing as soon as possible, depending on the tolerance of the patient. The patients were followed up clinically and radiologically at regular intervals, initially monthly, for the first six months and then every three months, for progress of union, for a minimum period of 6 months. Postoperative radiological assessment included degree of sliding, varus collapse, fracture union, and tip apex distance (TAD) evaluation. The clinical outcome was rated as per the Salvati and Wilson scoring system at the minimum of six months. Results were graded as excellent (score >31), good (score 24-31), fair (score 16-23), and poor (score <16). Final radiological evaluation included any nonunion, malunion, screw cutout and implant breakage, AVN of the femoral head, and the extent of sliding collapse.

\section{RESULTS}

A series of 33 osteoporotic intertrochanteric fractures were operated with cement augmented dynamic hip screw. The average age in this series was 78.93 years. Maximum age was 92 years. Minimum age was 65 years. Most of the patients were between 71-80 years of age $(60.61 \%)$.

Out of 33 cases 13 were males $(39.39 \%)$ and 20 were females $(60.61 \%)$. Female:Male ratio was 1.54:1.The fractures were more on right side. Right to left ratio was 1.36:1.The most common cause of trauma was slip and fall (28 cases, $84.85 \%$ ) followed by RTA (5 cases, $15.15 \%)$. Incidence of associated fractures was 8 cases (24.24\%). These included fracture pubic ramus, fracture colles, fracture clavicle and fracture neck of humerus $(\mathrm{NOH})$. Majority of fractures of type AO 31-A2 (16 cases, $48.48 \%$ ) as given in Figure 6.

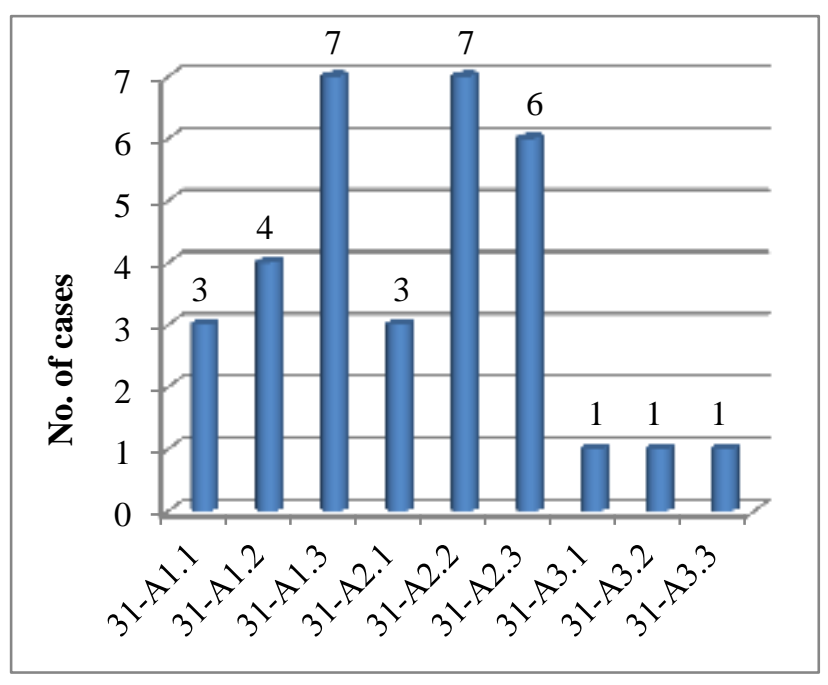

Figure 6: Fracture distribution a/c to AO classification.

15 cases $(45.45 \%)$ had associated medical problems. The most common was hypertension (6 cases, 18.18\%), followed by diabetes mellitus (5 cases, $15.15 \%)$ and chronic obstructive pulmonary disease (4 cases, $12.12 \%$ ). Total 33 patients were taken for the study they were followed for minimum 6 months and at 6 months the clinical outcome was rated as per the Salvati and Wilson scoring system. One patient lost to follow-up. Results were graded as excellent (score >31), good (score 24-31), 
fair (score 16-23), and poor (score <16). Clinical result was given according to Salvati and Wilson scoring as shown in Figure 7.

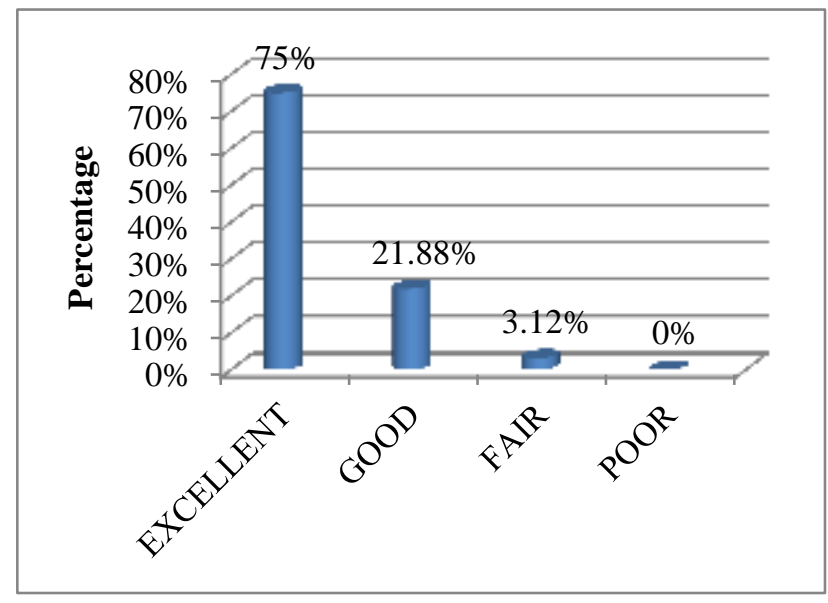

Figure 7: Clinical results.

\section{DISCUSSION}

The Intertrochanteric fractures are one of the most common fractures of the hip especially in the elderly with osteoporotic bones. It usually occurs due to low-energy trauma like simple fall. The incidence of hip fractures occurring worldwide has been expected to increase from 1.66 million in 1990 to 6.26 million in 2050 and this can be explained by increase in life expectancy. ${ }^{20}$

Management of these osteoporotic fractures in elderly age group pose a serious problem. Surgical management of trochanteric fractures aims at restoring the pre-fracture functional status of patients as soon as possible, to avoid problems of prolonged recumbencey. However, primary stabilization with standard dynamic hip screw is not always free from complications especially in osteoporotic fractures. In elderly patients qualitative deterioration of bone (osteoporosis) in spite of being a major risk factor for hip fractures, also contribute to the failure of fracture fixation in elderly patients on account of excessive collapse and lag screw cut-out from the superior aspect. $^{9,10}$ Sliding hip screw successfully address the issue of femoral head penetration, which was the problem with earlier fixed devices. ${ }^{21}$ Despite the success of dynamic hip screw in treating intertrochanteric fractures, there were certain issues which need to be addressed, as per the previous studies those potential issues were not even addressed by intramedullary fixation devices. An obvious means to improve the fixation of a cancellous bone screwis to provide strong anchorage surrounding the threaded portion of lag screw. Implant augmentation with cement has been used in fracture fixation since the use of PMMA in $1962 .{ }^{22}$ Clinical as well as biomechanical studies have demonstrated that the adequate use of PMMA cement provides rapid weight-bearing stability to the fracture fixation. ${ }^{18,16}$
We have conducted a prospective comparative study to evaluate the efficacy of PMMA augmented DHS in elderly osteoporotic patients with intertrochanteric fractures.

The average age in this series was 78.93 years (65-92 years). Most of the patients were between 71-80 years of age $(60.61 \%)$. Female predominated with a ratio of 1.54:1. Other studies also have shown that these fractures are more common in elderly age group with female predominance. $^{23}$

Most fractures were on right side (57.58\%). Average Tscore on DEXA scan was $-2.87(-2.5$ to -3.2$)$. There were 8 cases of associated fractures (fracture pubic rami, fracture colles, fracture neck of humerus, fracture clavicle). 15 cases had associated medical problems like hypertension, diabetes mellitus and chronic obstructive pulmonary disease.

In our study commonest mode of injury was slip and fall $(84.85 \%)$ as compared to Gupta et al having fall as the mode of injury in $85 \%$ of cases. ${ }^{23}$ Fall from same level at home being the most common aetiology for elderly female osteoporotic hip fractures, so there is an urgent need to develop preventive strategies, particularly in the developing countries like India.

To classify these fractures we have used AO classification system in our study, which is the most referenced classification in recent scientific articles and is a derivative of Muller classification. ${ }^{24}$

In our study, the average DEXA-t score was $2.87(-2.5$ to $-3.2)$, as compared to the average $\mathrm{T}$ score $2.8(-2.5$ to 3.4 ) in the study of Gupta et al. ${ }^{23}$

Tip apex distance predicts the lag screw position within the femoral head and is believed to be an independent predictor of lag screw cut out. In our study average tip apex distance of $19.91 \mathrm{~mm}(11-29 \mathrm{~mm})$ as compared to the average TAD of $20.8 \mathrm{~mm}$ in the study of Gupta et al with no screw cut-out, there were no screw cut-out in our study too. $^{23}$

In our study there was no sliding collapse in cemented DHS in accordance with the study of Gupta et al, by Lee et al and previous other studies. ${ }^{23,25}$ In our study there was no varus collapse accordance with the studies by Lee et al, Kim et al. ${ }^{25,26}$

Cement-augmented DHS have a different failure mode than screw cut-out in conventional DHS. Failures tended to be more related to delayed union, non-union and resultant side plate construct failure as concluded by $\mathrm{Wu}$ $\mathrm{MH}$ et al. ${ }^{27}$ In our study there were no cases of nonunion, the average time to union was 14.12 (12-17) weeks, and there was no case of side plate construct failure. 
Amount of cement and its placement also have an impact on the cement related complications such as heat necrosis

and ineffectiveness of dynamic hip screw mechanism. Cheng et al concluded that, complications in their series of intertrochanteric fractures were due to inappropriate placement and excessive amount of PMMA cement, Boner et al evaluated the risk of thermal necrosis when augmenting the implant purchase with PMMA. ${ }^{28,29}$ They concluded no risk of thermal necrosis at the PMMA/bone interface or in the surrounding bone upto $6.0 \mathrm{cc}$ PMMA. In a study by Lee et al using cement augmentation with DHS, with an average amount $13.7 \mathrm{ml}$ of PMMA. ${ }^{25}$ It has been recognized that bone necrosis is dose dependent, so it is advisable to use a minimum amount of bone cement. In our study we have used 4-5 ml of PMMA and there were no cases of thermal necrosis and avascular necrosis.

One of the major concerns during cement injection is the penetration of the cement into the joint. It is therefore important that the guide wire reach only the sub-chondral bone and not penetrate into the joint and position of guide wire should be central in both radiological views. We have injected cement through injection type syringe after wire removal in contrast to the study of Gupta et al where guide wire was kept in situ during cement injection with their custom made gun. ${ }^{23}$ There was no instance of cement penetration and difficulty in implant positioning in our study.

Cement augmentation added another step to the surgical procedure and prolonged our operating time by approximately six to seven minutes (the mean duration of operation was $68.00 \mathrm{~min}(58-74 \mathrm{~min})$ in contrast to four to five minutes in the study of Gupta et al. But in our study the difference was not statistically significant. Intra-operative bleeding is in part related to the operating time, but if proper haemostasis is achieved, there is hardly any extra blood loss during surgery, on account of cement augmentation.

In our study augmentation with PMMA provided a modest reduction in pain, improvement in quality of life, early weight bearing and lower overall complication rate during course of healing . This was in accordance with the studies by Gupta et al, Lee et al, Dall'Oca et al and other previous studies. $^{23,25,28}$

Final clinical results as evaluated by Salvati and Wilson score were excellent in 24 cases $(75 \%)$, good in 7 cases $(21.88 \%)$ fair in 1 case $(3.12 \%)$ and poor in 0 case $(0 \%)$.

The strength of our study is that cases were operated by same surgeon and at a single centre, this shows that there was consistency in surgical technique and implant use in the study. This study introduces a new manner to introduce cement into the femoral head that is clinically relevant, with a negligible risk of cement penetration into hip joint and in an appropriate location.
Our study had limitation that the, number of patients were limited and follow up period was short. The information of this study can be used for patients and as a reference for further studies

\section{CONCLUSION}

On the basis of our prospective comparative study we conclude that the surgical management of intertrochanteric fractures with PMMA augmented DHS provide a stable fixation with moderate pain free early mobilisation and better outcome in osteoporotic patients without the complications of superior screw cut-out, sliding collapse, and with the appropriate placement of bone cement along with proper amount $(4-5 \mathrm{ml})$ of cement we can also reduce the cement related complications such as delayed healing, non-union, heat necrosis, and avascular necrosis.

PMMA being inert and non-biodegradable is likely to persist within the femoral head forever. Long term persistence of PMMA may influence the rate of bone remodelling by affecting bone metabolism and the trabeculae may be weakened by change in the mechanical environment. Thus, it is advocated that PMMA augmentation should only be used in elderly patients with osteoporosis and limited life expectancy, till long term results are available.

Funding: No funding sources Conflict of interest: None declared

Ethical approval: The study was approved by the institutional ethics committee

\section{REFERENCES}

1. Zuckerman JD. Hip fractures. New Eng. Journal of medicine. 1996;334:1519-25.

2. Fox KM, Magaziner J, Helbel JR, Kenzora JE, Kashner TM. Intertrochanteric vs femoral neck fractures : differential characteristics, treatment and sequelae. J. Gernontol. A Biol Sci Med Sci. 1999;54:635-40.

3. Alffram PA. An epidemiologic syudy of cervical and trochanteric fractures of the femur in an urban population: Analysis of 1664 cases with special referances to etiologic factors. Acta Orthop Scand. 1964;65:9-109.

4. Gallagher JC, Melton LJ, Riggs BL, Bergstrath E. Epidemiology of fractures of the proximal femur in Rochester, Minnesota. Clin Ortop. 1980;150:16371.

5. Mannius S, Mellstrom D, Oden A, Rundgren A, Zetterberg C. Incidence of hip fractures in Western Sweden 1974-1982. Comparison of rural and urban populations. Acta Orthop Scand. 1987;58:38-42.

6. Koval KJ, Zuckerman JD. Current concepts review: Functional recovery after fracture of the hip. JBJS. 1994;76:751. 
7. Desjardins AL, Roy A, Paiement G, Newman N, Pedlow F, Desloges D, et al. Unstable intertrochanteric fracture of the femur. JBJS. 1993;75(3):445-7.

8. Kenneth JV, Robert VC. Intertrochanteric fractures. Rockwood and Green's Fractures in Adults. 6th ed. Philadelphia, USA. Lipincott Williams and Wilkins; 2006: 1794-1825.

9. Adams CI, Robinson CM, Court-Brown CM, McQueen MM. Prospective randomized controlled trial of an intramedullary nail versus dynamic screw and plate for intertrochanteric fractures of the femur. J Orthop Trauma. 2001;15:394-400.

10. Bridle SH, Patel AD, Bircher M, Calvert P. Fixation of intertrochanteric fractures of femur. A randomized prospective comparison of the gamma nail and DHS. J Bone Joint Surg Br. 1991;73:330-4.

11. Green S, Moore T, Proana F. Bipolar prosthetic replacement for the management of unstable intertrochanteric hip fractures in the elderly. Clin Orthop Relat Res. 1987;224:169-77.

12. Bonnaire F, Weber A, Bösl O, Eckhardt C, Schwieger K, Linke B. "Cutting out" in pertrochanteric fractures-problem of osteoporosis? Unfallchirurg. 2007;110:425-32.

13. Clark DW, Ribbans WJ. Treatment of unstable intertrochanteric fractures of the femur: A prospective trial comparing anatomical reduction and valgus osteotomy. Injury. 1990;21:84-8.

14. Hersche O, Heim D, Bodoky A, Regazzoni P. Four fragment fractures of the proximal femur: Is the dynamic hip screw a suitable implant. Helv Chir Acta. 1989;56:577-80.

15. Gupta RK, Sangwan K, Kamboj P, Punia SS, Walecha P. Unstable trochanteric fractures: The role of lateral wall reconstruction. Int Orthop. 2010;34:125-9.

16. Bartucci EJ, Gonzalez MH, Cooperman DR, Freedberg HI, Barmada R, Laros GS. The effect of adjunctive methylmethacrylate on failures of fixation and function in patients with intertrochanteric fractures and osteoporosis. J Bone Joint Surg Am. 1985;67:1094-107.

17. Harrington KD. The use of methylmethacrylate as an adjunct in the internal fixation of unstable comminuted intertrochanteric fractures in osteoporotic patients. J Bone Joint Surg Am. 1975;57:744-50.

18. Muhr G, Tscherne H, Thomas R. Comminuted trochanteric femoral fractures in geriatric patients: The results of 231 cases treated with internal fixation and acrylic cement. Clin Orthop Relat Res. $1979 ; 138: 41-4$
19. Schatzker J, Ha'eri GB, Chapman M. Methylmethacrylate as an adjunct in the internal fixation of intertrochanteric fractures of the femur. $\mathbf{J}$ Trauma. 1978;18:732-5.

20. Dennison E, Mohamed MA, Cooper C. Epidemiology of osteoporosis. Rheumatic Disease Clinics of North America. 2006;32(4):617-29.

21. Kyle RF, Gustilo RB, Premer RF. Analysis of six hundred and twenty-two intertrochanteric hip fractures. The Journal of Bone \& Joint Surgery. 1979;61(2):216-21.

22. Müller ME. The use of synthetic resins in bone surgery. Archives of Orthopaedic and Trauma Surgery, with special emphasis on the teaching and the fracture orthopaedic surgical technique. 1962;54(5):513-22.

23. Gupta RK, Gupta V, Gupta N. Outcomes of osteoporotic trochanteric fractures treated with cement-augmented dynamic hip screw. Indian journal of orthopaedics. 2012;46(6):640.

24. Marsh JL, Slongo TF, Agel J, Broderick JS, Creevey W, DeCoster TA, et al. Classification/AO OTA Orthopaedic trauma association fracture and dislocation compendium. J Orthop Trauma. 2007;21(10):31-2.

25. Cho SH, Lee SH, Cho HL, Ku JH, Choi JH, Lee AJ. Additional fixations for sliding hip screws in treating unstable pertrochanteric femoral fractures (AO type 31-A2): short-term clinical results. Clinics in orthopedic surgery. 2011;3(2):107-13.

26. Steinberg GG, Desai SS, Kornwitz NA, Sullivan TJ. The intertrochanteric hip fracture. A retrospective analysis. Orthopedics. 1988;11(2):265-73.

27. Wu MH, Lee PC, Peng KT, Wu CC, Huang TJ, Hsu RW. Complications of Cement-Augmented Dynamic Hip Screws in Unstable Type Intertrochanteric Fractures-A Case Series Study. Chang Gung Med. J. 2012;35(4):345-52.

28. Dall'Oca C, Maluta T, Moscolo A, Lavini F, Bartolozzi P. Cement augmentation of intertrochanteric fractures stabilised with intramedullary nailing. Injury. 2010;41(11):1150-5.

29. Boner V, Kuhn P, Mendel T, Gisep A. Temperature evaluation during PMMA screw augmentation in osteoporotic bone-an in vitro study about the risk of thermal necrosis in human femoral heads. Journal of Biomedical Materials Research Part B: Applied Biomaterials. 2009;90(2):842-8.

Cite this article as: Chandan RK, Verma D, Meena RC, Husain J. Evaluation of osteoporotic trochanteric fractures treated with cement-augmented dynamic hip screw. Int J Res Orthop 2016;2:148-54. 